\title{
Sciendo
}

Administration, vol. 68, no. 3 (2020), pp. 45-54

doi: 10.2478/admin-2020-0015

\section{Building collaboration capability in the public sector}

\author{
Siobhán Bradley \\ Institute of Public Administration, Ireland
}

\section{Introduction}

The current and future operating environment in the public sector requires creativity in using limited resources more efficiently and finding new ways of working to address challenges. Increasingly, public servants need to apply 'whole of sector' or cross-sector partnership approaches to deliver more groundbreaking, holistic and enduring solutions to complex problems (Head \& Alford, 2015). These complex leadership challenges are acknowledged in Our Public Services 2020 (Department of Public Expenditure and Reform, 2017), which emphasises innovation and collaboration as ways to think and work differently to deliver better outcomes for citizens. A system-wide approach to collaboration, involving citizens and service users (Pless \& Maak, 2011), is a way to break the cycle of 'tried and tested' or 'quick fixes' to these complex or 'wicked' issues (Grint, 2008), delivering better outcomes and more sustainable, systemic cultural change (Belet, 2016).

A challenge for leadership development programmes is to build confidence, conviction and capability in senior leaders to think and work differently, to go beyond functional and organisational boundaries and 'tried and tested' approaches to policy formation and implementation. Another challenge is ensuring the transfer of 
learning from projects and development initiatives to the whole of an organisation (Jarvis et al., 2013).

In this paper we review how the Institute of Public Administration (IPA), together with the Criminal Justice Strategic Committee, designed the first ever Cross Agency Collaborative Leadership Development Programme for the Criminal Justice Sector. Drawing on the experience of delivering the programme in the three years 201720 , we provide a model for a comprehensive leadership development initiative that can support the enhancement of capabilities at an individual, collective (organisational) and systemic (sectoral) level, which are all necessary to instigate broad cultural change. We believe this model to be transferable to other sectors and environments.

\section{Criminal justice context and background}

The criminal justice strategy for 2016-19 (Department of Justice and Equality, 2016) included a range of complex national issues, e.g. immigration, citizenship, state security, equality and access to justice for all, which required the collaboration of multiple agencies. In addition, reviews of the sector (Effectiveness and Renewal Group, 2018; Toland, 2014) highlighted a need for greater cooperation, collective strategic thinking and cross-agency problem-solving and a clearer focus on value for the citizen. They also identified that a number of capability and systemic challenges hindered sectoral-wide collaboration and strategic problem-solving. Recognising that a number of bilateral collaborations were already in operation, e.g. Irish Prison Service and Probation Service Strategic Plan, the criminal justice sector wished to build a more pervasive culture of collaboration and more opportunities for cross-agency working in the sector.

The Criminal Justice Strategic Committee identified leadership capability as a critical element in ensuring the appropriate mindset and skillset to enable more collaboration and new ways of thinking about the strategic challenges the sector faced. In addition, they wished to enable people to address challenges in more innovative and crosscutting ways, spearhead cultural change to allow more pervasive change across the sector, identify more inter-agency problem-solving and develop capacity across a significant cohort to future-proof the sector.

The resulting development programme is aimed at senior leaders, drawn from criminal justice organisations such as An Garda Síochána; the Department of Justice and Equality; the Probation, Prison and 
Court Services; the Legal Aid Board; the Policing Authority; Forensic Science Ireland; and the Office of Director of Public Prosecutions.

\section{IPA/Criminal Justice Cross Agency Collaborative Leadership Development Programme design}

Working in partnership with the Criminal Justice Strategic Committee, the IPA designed a programme focused on building a cohesive, collective understanding of collaboration and how this translates into practice in the criminal justice sector.

In designing the programme, the IPA could draw on experience in other jurisdictions, in particular a study into collaborative practice in the UK public sector by the Institute for Government (Miles \& Trott, 2011). This research highlights a range of lessons, and thus factors, necessary for successful collaborations. The four key lessons include the need for organisations to have a common purpose, a need to take a whole-systems approach to thinking and planning, a commitment to shared power and the need to incorporate a service user's perspective in order to stimulate change. According to their research, neglecting any one of these four core themes has a negative impact on collaboration and they found 'sharing power' was perceived as the hardest one to do well.

Typically, the individual is the focus of learning on leadership development programmes, with the aim that new collective behaviours, and thus cultural change, will be achieved through sufficient numbers attending a programme. Taking an innovative approach, however, this programme focuses on learning through the collective experience. It attempts to replicate the 'real work environment', and from the experience of working together, each individual identifies or understands their development needs.

This collective experience involves group work, where participants are randomly assigned to cross-agency project teams to look at strategic, sectoral challenges, identified by the Criminal Justice Strategic Committee. Projects provide an opportunity for participants to work outside of normal functional and organisational responsibilities in order to think holistically about issues of relevance to all the agencies involved in the programme.

This cross-organisational collaboration provides a platform to build relationships, a critical step towards building trust (Vangen \& Huxham, 2003b). The shared, lived collaborative programme 
experience (Kempster \& Parry, 2004) is designed to deliberately surface the natural tensions which arise in collaboration and provide a forum to observe behaviours and dynamics in practice (Mitchell et al., 2015).

Participants attend four two-day modules throughout the academic year. The modules are designed to support the collaborative group project process with inputs on skills and techniques for effective collaboration, leadership and leadership of change. Participants are also supported in their individual learning and development with a 360 degree behavioural diagnostic ${ }^{1}$ and individual coaching.

Importantly, thinking and working differently also involves incorporating stakeholders into the process of problem review and solution identification (Heifetz \& Linsky, 2002) in a co-created and collaborative process (Ferdig, 2007). It also requires participants to develop courage to address the real issues in persistent and recurring challenges (Reardon, 2007) and an ability to navigate the ambiguity of working with unclear answers (Grint, 2008) when addressing issues that are 'vu jadé' (never seen before) (Weick, 1993).

Another critical programme element is the active involvement of the Criminal Justice Strategic Committee and senior managers across the participating organisations, which demonstrates their commitment to cultural change. Their involvement is incorporated into the programme in a number of ways. Senior managers promote the programme, supporting participation of one to two of their staff each year. They are also visibly and actively present throughout the programme and at the launch and conclusion sessions. The conclusion session involves participants presenting the outcomes of their projects to the authorising body, the Strategic Committee and other senior managers in participating organisations. This is to ensure accountability for project outcomes and encourage integration of fresh thinking from the project process into sectoral thinking and planning. Consistent with wider research, and specifically with the findings in Boyle et al. (2019), the support and imprimatur of project sponsors (in this case from the Strategic Committee) are seen as critical to the success of the programme.

\footnotetext{
${ }^{1}$ Participants undertake the Leadership Effectiveness Assessment, which allows them to benchmark their leadership practices against twenty-two behaviours, categorised into six areas of leadership practice. Critical to their learning is the (anonymous) feedback from their boss, peers and direct reports, complementing their perspectives of self.
} 
Together, these supports aim to challenge thinking, to encourage fresh perspectives, courage and resilience to enable new ways of working, and to develop skills and approaches to drive innovative and 'joined-up' solutions. This thus enhances confidence and conviction in collaborative practice (Vangen \& Huxham, 2003a).

\section{Research}

A deliberate aim of the programme is to undertake practice-led research to expand our understanding of collaboration in the Irish context. The criminal justice programme offers an opportunity to observe, over the longer term, participants' 'lived experience' (Kempster \& Parry, 2004) of collaboration to gain a better understanding of what supports and hinders collaboration and the leadership competencies required to work across boundaries in the Irish public sector.

Research data are gathered in three ways - pre-programme, postmodule during the programme and post-programme. Lessons are already emerging in respect of collaborative practice in Ireland in the criminal justice system and the necessary elements for effective collaborative leadership development. The findings below illustrate lessons learned to date.

\section{Pre-programme}

As participants are typically already involved in collaboration, albeit more at a bi-agency level, they receive a pre-programme questionnaire to capture their experience of collaboration in the criminal justice system.

We found that their experience of collaboration mirrored wider research, including that of the Institute for Government in the UK (Miles \& Trott, 2011). Programme participants identified that there was a lack of a common goal and a shared vision for the sector, which translated into separate business planning processes, limited joint problem-solving, lack of reliable or even available data, and a limited ability to share information across organisational boundaries - all of which are vital for joint discussions and decisionmaking.

Many if not all of us were probably waiting for a cross-sectoral opportunity such as this and the course proves that there is an appetite across the sector for greater cooperation and collaboration. 
Also, despite much bilateral interaction, participants admitted poor knowledge and poor trust of other criminal justice organisations. They did not understand the challenges under which other organisations work nor their organisational cultures, which influences decisionmaking, communications and collaborative behaviours.

Collaboration requires an understanding of the other organisation's perspectives and challenges.

When we all interact as part of our day jobs we are inclined to try and protect our own bodies' interests and it may be that we rarely move out of our own silos.

Participants found from their collaboration experience that progress is often stalled or halted by the absence of those with sufficient authority or responsibility to move the process and decisions forward.

A challenge was also not having decision-makers as part of the collaborative process, so that the process becomes a consultative forum, slowing progress of ideas.

These comments, as mentioned previously, reflect findings in other research, prompting decisions in programme design. For example, participants are deliberately not involved on programme collaborative projects where they have prior knowledge of the topic, to allow fresh thinking and broader perspectives to be included. Similarly, participants from agencies are encouraged to be team leads in acknowledgement of the hierarchical challenges between department and agencies mentioned later.

\section{Post-module during programme}

Questionnaires are also included at each of the four two-day programme modules. The individual-based questionnaire ascertains perceived behavioural change and the impact of such on how participants think about problems and collaborate together. It also captures lessons from the collaborative process and ways to improve programme content and methodologies. Taking a 'co-creation' approach, there is flexibility in the programme design to cater to the specific needs of participants each year. For example, issues may arise in the project process around which participants would like more support and around specific skills areas, which warrant further attention. 


\section{Post-programme}

Participants complete a post-programme questionnaire immediately on completion of the programme. They also complete a questionnaire six months post programme to better understand the impact of the programme from their lived experience (Kempster \& Parry, 2004) on the use of collaborative working in their real work environments.

\section{Individual-level lessons}

Initial steps have built confidence in a new way of working, enabling participants to identify appropriate behaviours in line with the collaboration context. Uniquely, they practise these behaviours through the project process, accelerating the transfer of learning to the real work environment.

I have learned more from listening to my colleagues on the programme than I could have ever learned elsewhere.

I have really valued the working relationships with my project team, who bring a wealth of skills and some challenges for me.

As with any learning process, participants experience some stumbling blocks.

I hit a brick wall when I suggested to my project team that we share our project details/outcomes with the other project groups in advance of the presentation ... more work to be done!

The task feels harrowing at times, the sense of shared purpose motivates and uplifts.

The feedback, however, is overwhelmingly positive, reaffirming the value of the programme.

The course itself is an example of collaboration in action ... I personally have used the contacts gained to help me with traction on some crossagency initiatives and in turn I have assisted others on the course. This is all 'hidden' activity, which will generate a return for years to come.

\section{Collective/sectoral-level lessons}

Through the process of working together on sectoral challenges, participants overcome issues which inhibit integrated policymaking and the delivery of efficient and effective services. 
This course very quickly placed us all on an equal footing and by utilising a neutral setting, broke down any barriers that may have existed, real or perceived.

A group of individuals from across the criminal justice sector to spend time with each other, where we did not have to defend our own patch.

A challenge for collaboration and for the programme is the inherent hierarchy in the system, where agencies tend to seek guidance from the department and where the department is used to providing that clear direction.

On the other hand, the programme and particularly the collaborative projects have become a focus of broader engagement and a forum for wider relationship building and networking in the sector. For example, the Department of Justice and Equality has developed a number of initiatives to share learning from the programme projects across the sector, and the recommendations from the collaborative projects feed into discussions on policy formation or improvement.

There is a growing realisation that many strategic issues discussed in the projects will require a 'whole of government' approach to deliver change, which warrants consideration for how to expand collaborative practice into other sectors and across government.

\section{Conclusion}

This programme focuses on learning from the collective, attempting to replicate the 'real work environment', where individuals are encouraged to gain deeper personal insight and develop better skills to work in a collective, collaborative context. The project process is therefore a forum for reflection and observation, for skills practice and learning, and an avenue to generate fresh thoughts and tangible outcomes for the sector.

In seeing the value of thinking, planning and acting strategically in 'whole of sector' terms, participants can gain new insights on common strategic challenges and a better understanding of the impact of systemic collaboration shortfalls on policy formation and implementation across the sector. This in turn encourages earlier identification of issues and the development of more robust solutions to issues. 
While the programme was instigated three years ago, it addresses current challenges and provides a model for cross-organisational/ cross-sectoral development initiatives. As we continue to face challenges never seen before at a global level, such as the impact of Covid-19, and nationally, for example, public sector change, health and housing, it seems an opportune time to try a new approach to working and capability development. Echoing the conclusions of the UK's Institute for Government report (Miles \& Trott, 2011), 'collaboration is hard, but it is worth it'.

\section{References}

Belet, D. (2016). Enhancing leadership skills with action learning: A promising way to improve the effectiveness of leadership development. Development and Learning in Organizations: An International Journal, 30 (6), 13-15.

Boyle, R., O'Riordan, J., Shannon, L., MacCarthaigh, M., \& Thomas, P. (2019). Evaluation of the GOAL Programme for Public Service Reform and Innovation. Retrieved from https://www.ipa.ie/_fileUpload/ Documents/Summative_Report_CES_Final_14Oct19.pdf [26 April 2020].

Department of Justice and Equality (2016). A safe, fair and inclusive Ireland. Strategy statement 2016-2019. Retrieved from www.justice.ie [26 April 2020].

Department of Public Expenditure and Reform (2017). Our public services 2020. Retrieved from https://www.ops2020.gov.ie/ [26 April 2020].

Effectiveness and Renewal Group (2018). Report of the Effectiveness and Renewal Group for the Department of Justice and Equality. Retrieved from http://www.justice.ie/en/JELR/Pages/Effectiveness_and_Renewal_Group_ Reports [26 April 2020].

Ferdig, M. A. (2007). Sustainability leadership: Co-creating a sustainable future. Journal of Change, 7 (1), 25-35.

Grint, K. (2008). Wicked problems and clumsy solutions: The role of leadership. Clinical Leader, 1 (2).

Head, B. W., \& Alford, J. (2015). Wicked problems: Implications for public policy and management. Administration and Society, 47 (6), 711-39.

Heifetz, R., \& Linsky, M. (2002). Leadership on the line. Boston: Harvard Business School Press.

Jarvis, C., Gulati, A., McCririck, V., \& Simpson, P. (2013). Leadership matters: Tensions in evaluating leadership development. Advances in Developing Human Resources, 15 (1), 27-45.

Kempster, S., \& Parry, K. W. (2004). The lived experience as leadership development. Retrieved from http://works.bepress.com/ken_parry/22/ [26 April 2020]. 
Miles, E., \& Trott, W. (2011). Collaborative working [InsideOUT series]. London: Institute for Government.

Mitchell, G. E., O'Leary, R., \& Gerard, C. (2015). Collaboration and performance: Perspectives from public managers and NGO leaders. Public Performance and Management Review, 38 (4), 684-716.

Pless, N. M., \& Maak, T. (2011). Responsible leadership: Pathways to the future. Journal of Business Ethics, 98, 3-13.

Reardon, K. K. (2007). Courage as a skill. Harvard Business Review, July, 58-64.

Toland, K. (2014). Report of the Independent Review Group on the Department of Justice and Equality. Dublin: Department of Justice and Equality.

Vangen, S., \& Huxham, C. (2003a). Enacting leadership for collaborative advantage: Dilemmas of ideology and pragmatism in the activities of partnership managers. British Journal of Management, 14, 61-76.

Vangen, S., \& Huxham, C. (2003b). Nurturing collaborative relations. Journal of Applied Behavioural Science, 39 (1) 5-31.

Weick, K. E. (1993). The collapse of sensemaking in organisations. Administrative Science Quarterly, 38 (4), 628-52. 